\title{
Incidence of and risk factors for totally implantable vascular access device complications in patients with gastric cancer: A retrospective analysis
}

\author{
MITSUYOSHI OKAZAKI, KATSUNOBU OYAMA, JUN KINOSHITA, TOMOHARU MIYASHITA, \\ HIDEHIRO TAJIMA, HIROYUKI TAKAMURA, ITASU NINOMIYA, SACHIO FUSHIDA and TETSUO OHTA \\ Department of Gastroenterological Surgery, Division of Cancer Medicine, \\ Graduate School of Medical Science, Kanazawa University, Kanazawa, Ishikawa 920-8641, Japan
}

Received August 29, 2018; Accepted June 27, 2019

DOI: $10.3892 /$ mco.2019.1897

\begin{abstract}
Totally implantable vascular access devices(TIVADs) are often used to administer chemotherapy by prolonged intravenous infusion. The objective of the present study was to investigate the incidence of long-term complications and identify risk factors associated with TIVAD placement in patients with gastric cancer. A total of 121 patients with gastric cancer who had undergone 150 TIVAD placement procedures for chemotherapy or supportive care were enrolled in the present retrospective cohort study. A number of risk factors were analyzed, including age, sex, hypertension, diabetes mellitus, history of thrombosis, body mass index, disease stage, and site and purpose of TIVAD. In total, 40 TIVADs (26.7\%) developed long-term complications, of which 27 (18.0\%) were infections, seven $(4.7 \%)$ were catheter-related deep vein thrombosis (CR-DVT), and six (4.0\%) were obstructions. Chemotherapy was associated with an increased rate of infectious adverse events (odds ratio 2.925; 95\% CI, 1.104-7.750; $\mathrm{P}=0.031$ ) according to the multivariate analysis. CR-DVT occurred more frequently in upper arm ports than in chest wall ports; however, this difference was not statistically significant ( 7.5 vs. $0.0 \%$; $\mathrm{P}=0.084$ ) according to the univariable analysis. All CR-DVTs developed in the upper arm sites. Chemotherapy and the upper arm site were associated with long-term complications in patients with TIVAD. However, further studies are needed to confirm the findings of the present study and to determine the reasons for the high incidence of long-term complications in these patients.
\end{abstract}

Correspondence to: Dr Mitsuyoshi Okazaki, Department of Gastroenterological Surgery, Division of Cancer Medicine, Graduate School of Medical Science, Kanazawa University, 13-1 Takara-machi, Kanazawa, Ishikawa 920-8641, Japan E-mail: mitsuyoshi0610@yahoo.co.jp

Key words: totally implantable vascular access devices, long-term complications, infectious adverse events, catheter-related deep vein thrombosis, gastric cancer

\section{Introduction}

Gastric cancer is the fourth most frequently diagnosed cancer and the second leading cause of cancer death worldwide (1). The majority of patients with advanced cancer require chemotherapy. Furthermore, supportive care measures, such as medication for preventing chemotherapy-related adverse effects, nutritional support and symptom-relieving drugs have become increasingly important during different phases of cancer treatment (2-4). Implantation of a totally implantable vascular access device (TIVAD) enables repeated administration of chemotherapeutic drugs, parenteral nutrition and intravenous infusion, without multiple peripheral venous punctures and venous toxicities $(5,6)$. TIVADs have been extensively endorsed and used, and the procedure for implanting them is safe and effective $(7,8)$.

TIVADs are placed via the subclavian, external or internal jugular vein through the anterior chest wall, or via the basilic vein through the upper arm; the optimal TIVAD insertion site is controversial (9-23). Placement in the anterior chest wall has been the preferred approach; the advantages of this route include high stability of the system and a low incidence of infection (9). However, complications associated with the operative procedure, such as pneumothorax, arterial puncture and vascular injury, occur in $0.3-15.8 \%$ of patients (9-11). For this reason, upper arm sites have been increasingly used; the placement procedure is simple with fewer operative complications, and these sites have cosmetic advantages and an absence of possible interference with radiation therapy (12-14). However, the upper arm route is associated with risk of long-term complications, including catheter-related deep vein thrombosis (CR-DVT), infectious adverse events and mechanical complications (15-18). Furthermore, previous studies have reported that the risk of CR-DVT in patients with cancer is four- to seven-fold that of patients without cancer (19-22). However, although long-term complications are common and potentially serious, the incidence and risk factors in patients with cancer remains unclear. The purpose of the present study was to investigate the incidence of long-term complications and identify risk factors associated with TIVAD placement in patients with gastric cancer. 


\section{Patients and methods}

Study cohort and data collection. The present study cohort comprised 121 patients with gastric cancer who had undergone TIVAD placement at Kanazawa University Hospital between January 2010 and September 2014; 150 TIVAD ports were placed for chemotherapy and supportive care. Implantation sites were chosen by the surgeon performing the procedure. For the purpose of analysis, each TIVAD placement was counted as a new event. Therefore, all analyses were performed according to TIVAD placements rather than to individual patients. Eligible patients underwent TIVAD placement via the chest wall or upper arm and were followed up for $\geq 3$ years, or until TIVAD removal or death at Kanazawa University Hospital. The surgical procedure and its possible benefits and complications, as well as alternative procedures, were explained to patients, and all patients provided written informed consent before undergoing placement of a TIVAD. The present study was approved by the Research Ethics Committee of Kanazawa University.

Ports and catheters. Open-end type catheters and BARD Slim-Ports (Bard Access Systems) were used initially, and the Vital-Port Vascular Access System (Cook Medical, LLC) later in the study period. Port systems used for the chest and arm sites weighed 8 and $2.5 \mathrm{~g}$, and were 0.5 and $0.2 \mathrm{ml}$ in internal volume, respectively.

Placement of TIVADs. All TIVADs were placed under local anesthesia at the port site using maximal sterile precautions. Routine antibiotic and antithrombotic prophylaxis were not administered. The surgical fields were sterilized with $10 \%$ povidone-iodine.

The chest TIVADs were inserted through the subclavian or external jugular vein. Puncture of the subclavian vein was carried out under real-time ultrasonography, whereas puncture of the external jugular vein was via surgical exposure by cut-down. After confirmation of the backflow of blood, a catheter was advanced into the superior vena cava and the catheter tip was inserted to the level of the tracheal bifurcation under $\mathrm{X}$-ray fluoroscopic examination. A subcutaneous pocket was established on the lateral side of the anterior chest wall and the inserted port connected to the catheter through a subcutaneous tunnel. The wound was closed with 4-0 absorbable sutures. Postoperative chest radiography was routinely carried out to determine the position of the catheter tip.

The arm TIVADs were inserted through the basilic vein. Portable ultrasonography was routinely performed before TIVAD placement to identify a suitable vein for insertion. After puncturing the vein with a 22-gauge elastic needle, a catheter was advanced into the superior vena cava. The catheter tip was inserted to the level of the tracheal bifurcation by X-ray fluoroscopic examination. A subcutaneous pocket was shaped distal to the puncture site and the inserted port connected to the catheter in the same manner as the chest port.

Maintenance and follow-up. TIVAD use was started 1-3 days after implantation. Saline was injected to check for leakage or occlusion of the catheter. A semipermeable transparent dressing was used to cover the needle. In patients requiring continuous infusion, the infusion line and needle were changed once a week. Heparinized saline $(10 \mathrm{ml} ; 100 \mathrm{IU} / \mathrm{ml})$ was injected as a flush solution before removing the needle. If the TIVAD was not used for more than a month, heparinized saline was administered monthly. Postoperative ultrasonography was not performed during follow-up provided the patients were asymptomatic.

Study outcomes. The primary end-point of the present study was the cumulative incidence of long-term complications and the secondary end-point was the cumulative incidence of risk factors for long-term complications. Infectious complications included bloodstream infection (BSI) and port-pocket infection. BSI was defined as evidence of inflammation, such as fever or positive blood cultures associated with a long-term venous port. Port-pocket infection was diagnosed on the basis of purulent discharge, tenderness and erythema. Other complications, including CR-DVT and obstructions, were identified. CR-DVT was defined as swelling, redness and tenderness, and diagnosed thrombi were confirmed by ultrasonography. A total of seven variables were analyzed by univariable logistic regression, namely age, sex, risk factor (including hypertension, diabetes mellitus and previous history of thrombosis), body mass index (BMI), disease stage (23), site and purpose of port placement.

Statistical methods. All data were analyzed using the computer software package SPSS 10.0 (SPSS, Inc.). Categorical data were compared using the $\chi^{2}$ test. Relevant patient characteristics and baseline variables were summarized using descriptive statistics. Univariable and multivariable logistic regression analyses were performed to identify risk factors. $\mathrm{P}<0.05$ was considered to indicate a statistically significant difference.

\section{Results}

Patient characteristics. In total, 96 of the 121 patients underwent only one TIVAD placement procedure, 21 underwent two procedures and 4 underwent three procedures (Table I). The main characteristics of the included patients are summarized in Table II. The hospital records of 150 TIVAD placements, performed at Kanazawa University Hospital (89 males, 61 females; median age 63 years, range 26-87 years) in 121 patients were retrospectively analyzed. They comprised 57 chest wall procedures (38.0\%) and 93 upper arm procedures $(62.0 \%)$. A total of $88(58.7 \%)$ procedures were for chemotherapy and 62 (41.3\%) for supportive care (Table II).

Incidence of late complications. Table III presents the long-term complications after TIVAD placement. In total, 40 TIVADs (26.7\%) were associated with long-term complications, of which $27(18.0 \%)$ were infections, seven (4.7\%) were CR-DVT, and six (4.0\%) were obstructions. There were no port fractures, pinch-offs or catheter tip displacements.

Risk factors for long-term complications. Infectious adverse events occurred significantly more frequently with chemotherapy than with supportive care ( 23.9 vs. $9.7 \% ; \mathrm{P}=0.044$; Table IV). Furthermore, according to the multivariable analysis of risk factors with P-values $<0.2$ in the univariable analysis by logistic regression, chemotherapy was associated 
Table I. Number of totally implantable vascular access device placment procedures per patient $(n=121)$.

\begin{tabular}{lrr}
\hline Placement procedures & $\mathrm{n}$ & $\%$ \\
\hline One time & 96 & 79.3 \\
Two times & 21 & 17.4 \\
Three times & 4 & 3.3 \\
\hline
\end{tabular}

Table II. Patient characteristics.

\begin{tabular}{lcr}
\hline Characteristic & $\mathrm{n}$ & $\%$ \\
\hline Sex & & \\
Male & 89 & 59.3 \\
Female & 61 & 40.7 \\
Age, mean (range) & $63(26-87)$ & \\
$\quad<70$ years & 109 & 72.7 \\
$\geq 70$ years & 41 & 27.3 \\
Risk factor & \\
+ & & 35.3 \\
- & 53 & 64.7 \\
BMI & 97 & 93.3 \\
$<25$ & & 6.7 \\
$\geq 25$ & 140 & \\
TNM & 10 & 11.3 \\
I, II, III & & 88.7 \\
IV, recurrence & 17 & \\
Site & 133 & 62.0 \\
Chest & & \\
Upper arm & 58.0 \\
Purpose & 93 & \\
Chemotherapy & & \\
Supportive care & & \\
\hline
\end{tabular}

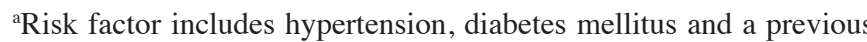
history of thrombosis. BMI, body mass index.

Table III. Incidence of late complications after totally implantable vascular access device placement $(n=150)$.

\begin{tabular}{lrr}
\hline Complication & $\mathrm{n}$ & $\%$ \\
\hline Total & 40 & 26.7 \\
Infection & 27 & 18.0 \\
CR-DVT & 7 & 4.7 \\
Obstruction & 6 & 4.0 \\
\hline
\end{tabular}

CR-DVT, catheter related deep vein thrombosis.

with an increased rate of infectious adverse events, with an odds ratio of 2.925 (95\% CI, 1.104-7.750; $\mathrm{P}=0.031$; Table IV).
CR-DVT occurred more frequently in patients with BMI $\geq 25$ than $<25$ (30.0 vs. $2.9 \%$; $\mathrm{P}=0.002$ ), in stage I-III than stage IV (11.8 vs. $3.8 \%$; $\mathrm{P}=0.037)$, in male than in female patients (7.9 vs. $0.0 \%$; $\mathrm{P}=0.064)$ and more often in the upper arm than the chest wall sites ( 7.5 vs. $0.0 \%$; $\mathrm{P}=0.084$; Table V); however, sex and site were not statistically significant risk factors. A multivariable analysis of risk factors was not conducted, as the study was too small. Notably, CR-DVTs occurred in upper arm sites; however, none occurred in the chest wall (Table V).

\section{Discussion}

In the present study, infectious adverse events and CR-DVT were identified as long-term complications of TIVADs in patients with gastric cancer. The incidence of infectious adverse events was greater with chemotherapy use (23.9\%) than with supportive care $(9.7 \%)$. Furthermore, the chest wall and arm sites had different safety profiles, CR-DVT occurring only in arm sites (7.5\%).

Risk factors for CR-DVT and infection associated with TIVAD placement belong to three categories: i) Catheter factors, such as the insertion site; ii) patient-related factors, such as presence of malignancy; and iii) medication factors, such as chemotherapy (22).

Catheter factors, including the insertion site, have been shown to be important; previous studies having reported an incidence of CR-DVT of $0.7-8.2 \%$ for arm ports $(24,25)$. Lin et al (26) reported that the left or right side of TIVAD placement is not associated with occurrence of CR-DVT; however, this factor was not assessed in the present study. At $4.7 \%$, the rate of CR-DVT was significantly higher for arm ports than chest wall ports, where no CR-DVTs developed. CR-DVTs may result in patient inconvenience and the need for anticoagulation therapy, early catheter removal and re-cannulation (15). Arm ports occupy a large proportion of the intravascular lumen as they are in peripheral veins (27). Repetitive arm movements can also contribute to the incidence of CR-DVT (28). Furthermore, TIVADs in the arm require a longer intravenous catheter than chest wall TIVADs (29). Therefore, prolonged contact between the catheter and the intravascular wall may result in endothelial damage, reduction in blood flow and consequent CR-DVT (22).

The second category of patient-related factors is also important. Patients with cancer, who are often immunocompromised and may be malnourished, have been reported to have a higher incidence of infectious complications (30-32) with a substantially higher risk of venous thromboembolism than patients without cancer (33-35). Trousseau (36) first reported the association between malignancy and venous thromboembolism as a documented cause of migratory CR-DVT in patients with cancer. Venous thromboembolism in patients with cancer is typically associated with hypercoagulability, endothelial damage, blood flow stasis, dehydration and malnutrition (37). The clotting process is exacerbated by direct interaction between cancer cells and endothelial cells, which activates blood cells, such as monocytes, macrophages and platelets $(34,38)$. Furthermore, the primary tumor site significantly affects the risk of venous thromboembolism; gastric cancer is associated with a high incidence of this complication $(19,39)$. In 
Table IV. Univariable and multivariable analyses of risk factors for infection incidence.

\begin{tabular}{|c|c|c|c|c|c|c|c|c|}
\hline \multirow[b]{2}{*}{ Characteristic } & \multirow[b]{2}{*}{$\mathrm{n}$} & \multirow[b]{2}{*}{ Yes } & \multirow[b]{2}{*}{ No } & \multirow[b]{2}{*}{$\%$} & \multirow{2}{*}{$\begin{array}{c}\text { Univariable analysis } \\
\text { P-value }\end{array}$} & \multicolumn{3}{|c|}{ Multivariable analysis } \\
\hline & & & & & & OR & $95 \% \mathrm{CI}$ & P-value \\
\hline Age, $<70 / \geq 70$ years & $109 / 41$ & $24 / 3$ & $85 / 38$ & $22.0 / 7.3$ & 0.064 & 2.825 & $0.784-10.188$ & 0.112 \\
\hline Sex,$M / F$ & $89 / 61$ & $15 / 12$ & $74 / 49$ & $16.9 / 19.7$ & 0.659 & & & \\
\hline Risk factor ${ }^{\mathrm{b}},+/-$ & $53 / 97$ & $8 / 19$ & $45 / 78$ & $15.1 / 196.6$ & 0.644 & & & \\
\hline $\mathrm{BMI},<25 / \geq 25$ & $140 / 10$ & $26 / 1$ & $114 / 9$ & $18.6 / 10.0$ & 0.798 & & & \\
\hline Stage, I-III/IV, REC & $17 / 133$ & $1 / 26$ & $16 / 107$ & $5.9 / 19.5$ & 0.296 & & & 0 \\
\hline Site, Chest/Arm & $57 / 93$ & $8 / 19$ & $49 / 74$ & $14.0 / 20.4$ & 0.441 & & & \\
\hline Purpose, Chemo/Supportive care & $88 / 62$ & $21 / 6$ & $67 / 56$ & $23.9 / 9.7$ & $0.044^{\mathrm{a}}$ & 2.925 & $1.104-7.750$ & $0.031^{\mathrm{a}}$ \\
\hline
\end{tabular}

${ }^{\mathrm{a}} \mathrm{P}<0.05$. ${ }^{\mathrm{b}}$ Risk factor includes hypertension, diabetes mellitus and a previous history of thrombosis. BMI, body mass index; OR, odds ratio; REC, recurrence; M, male; F, female.

Table V. Univariable analyses of risk factors for catheter-related deep vein thrombosis incidence.

\begin{tabular}{lccccc}
\hline Characteristic & $\mathrm{n}$ & Yes & No & $\%$ & P-value \\
\hline Age, $<70 / \geq 70$ years & $109 / 41$ & $6 / 1$ & $103 / 40$ & $5.5 / 2.4$ & 0.720 \\
Sex, M/F & $89 / 61$ & $7 / 0$ & $82 / 61$ & $7.9 / 0.0$ & 0.064 \\
Risk factor ${ }^{\mathrm{b}},+$ - & $53 / 97$ & $4 / 3$ & $49 / 94$ & $7.5 / 2.9$ & 0.406 \\
BMI, $<25 / \geq 25$ & $140 / 10$ & $4 / 3$ & $136 / 7$ & $2.9 / 30.0$ & $0.002^{\mathrm{a}}$ \\
Stage, I-III/IV, REC & $17 / 133$ & $3 / 4$ & $14 / 129$ & $11.8 / 3.8$ & $0.037^{\mathrm{a}}$ \\
Site, chest/arm & $57 / 93$ & $0 / 7$ & $57 / 86$ & $0.0 / 7.5$ & 0.084 \\
Purpose, chemo/supportive care & $88 / 62$ & $6 / 1$ & $82 / 61$ & $6.8 / 1.6$ & 0.273
\end{tabular}

${ }^{\mathrm{a}} \mathrm{P}<0.05$. ${ }^{\mathrm{b}}$ Risk factor includes hypertension, diabetes mellitus and a previous history of thrombosis. BMI, body mass index; OR, odds ratio; $\mathrm{REC}$, recurrence; $\mathrm{M}$, male; F, female.

the present study, CR-DVT occurred more frequently in male patients than in female patients, more often in those with BMI $\geq 25$ than BMI $<25$, and more often in stage I-III than stage IV. The risk associated with sex remains uncertain as findings of previous studies are conflicting; a higher risk for pulmonary embolism and deep venous thrombosis was reported for both men $(40,41)$ and for women (42). Obesity has long been a known risk factor for venous thromboembolism $(43,44)$. Similar to the present results, a number of previous studies have observed that being male and/or obese are risk factors for CR-DVT $(45,46)$. Typically, advanced disease stages cases are expected to have more CR-DVT (47); however, in the present study, contradictory results were obtained. This could not be considered in detail and requires further investigation in future studies.

Medication factors, such as chemotherapy, are risk factors for CR-DVT and infection $(19,4)$. Chemotherapy may damage the vascular endothelium, cause disequilibrium between procoagulant and anticoagulant molecules, induce apoptosis in tumor endothelial cells, activate cytokines, and increase tissue factor activity (48). The present results suggested that chemotherapy is a risk factor for infectious complications. Development of CR-DVT can also be promoted by central venous catheter-related infection in patients undergoing intensive chemotherapy (20). In the present study, an association between chemotherapy and
CR-DVT was not observed. However, careful maintenance of TIVADs for the purpose of chemotherapy is required.

The present study had several limitations. As it was a retrospective single-center study, the present results may not be applicable to other institutions, especially if the type of catheter used and protocol for catheter maintenance differ from those used at Kanazawa University Hospital. The types of catheter and the operation times have important impacts on late complications $(49,50)$. However, in the present retrospective study, it was not possible to evaluate these factors because detailed data had not been recorded. As the present study was not a randomized controlled study, the comparison between chest wall and upper arm ports is not definitive. Additionally, as only symptomatic conditions were recorded, asymptomatic complications could not be identified. Asymptomatic patients did not undergo ultrasonography during follow-up. Overt CR-DVT occurred only in patients with arm TIVADs and patients with chest TIVADs were almost completely asymptomatic. The incidence of asymptomatic CR-DVT is reportedly as high as $66 \%(51,52)$. Furthermore, the chemotherapy regimens or cumulative duration of port placement were not compared. Nevertheless, the present study identified an increased risk of infectious complications associated with TIVADs for chemotherapy and an increased risk of CR-DVT associated with arm TIVADs. 
In conclusion, the present study identified an association between the objective of chemotherapy and risk of central venous catheter-related infection. Therefore, these patients should be carefully monitored after TIVAD insertion. In addition, CR-DVT may be associated with the upper arm site. Taking the results of the present study and the risk of complications associated with the operative procedure into consideration, it may be necessary to choose the site for TIVAD insertion on an individual basis. However, the present findings require confirmation by a prospective randomized study, including evaluation of the quality of life of the patients. More specifically, to the best of our knowledge, an agreement has not yet been reached on the use of prophylactic anticoagulants and antibiotics in the management of TIVAD (14). Further studies are needed to determine whether such prophylaxis reduces the incidence of long-term complications.

\section{Acknowledgements}

Not applicable.

\section{Funding}

No funding was received.

\section{Availability of data and materials}

All data generated or analyzed during the present study are included in this published article.

\section{Authors' contributions}

$\mathrm{MO}, \mathrm{KO}$ and $\mathrm{JK}$ conducted the studies, participated in data collection, and drafted the manuscript. MO and $\mathrm{KO}$ performed the statistical analysis and participated in the design of the study. JK, TM, HTaj, HTak, IN, SF and TO analyzed and interpreted the data, and reviewed and revised the manuscript. All authors read and approved the final manuscript.

\section{Ethics approval and consent to participate}

The present study was approved by the Research Ethics Committee of Kanazawa University, and written informed consent for placement of TIVADs was obtained from every participant.

\section{Patient consent for publication}

Not applicable.

\section{Competing interests}

The authors declare that they have no competing interests.

\section{References}

1. Orditura M, Galizia G, Sforza V, Gambardella V, Fabozzi A Laterza MM,Andreozzi F, Ventriglia J,Savastano B,Mabilia A, et al: Treatment of gastric cancer. World J Gastroenterol 20: 1635-1649, 2014.
2. Schiffer CA, Mangu PB, Wade JC, Camp-Sorrell D, Cope DG, El-Rayes BF, Gorman M, Ligibel J, Mansfield P and Levine M: Central venous catheter care for the patient with cancer: American Society of Clinical Oncology clinical practice guideline. J Clin Oncol 31: 1357-1370, 2013.

3. Turcotte S, Dube S and Beauchamp G: Peripherally inserted central venous catheters are not superior to central venous catheters in the acute care of surgical patients on the ward. World J Surg 30: 1605-1619, 2006.

4. Viart H, Combe C, Martinelli T, Thomas J and Hida H: Comparison between implantation costs of peripherally inserted central catheter and implanted subcutaneous ports. Ann Pharm Fr 73: 239-244, 2015 (In French).

5. Goltz JP, Noack C, Petritsch B, Kirchner J, Hahn D and Kickuth R: Totally implantable venous power ports of the forearm and the chest: Initial clinical experience with port devices approved for high-pressure injections. Br J Radiol 85: e966-e972, 2012.

6. Alexander MD and Morrison HL: Power-injectable ports: Safety during placement, therapeutic use, and contrast administration during computed tomography procedures. J Vasc Access 13: 432-437, 2012.

7. Kock HJ, Pietsch M, Krause U, Wilke H and Eigler FW: Implantable vascular access systems: Experience in 1500 patients with totally implanted central venous port systems. World J Surg 22: 12-16, 1998.

8. Lorch H, Zwaan M, Kagel C and Weiss HD: Central venous access ports placed by interventional radiologists: Experience with 125 consecutive patients. Cardiovasc Intervent Radiol 24: 180-184, 2001

9. Vardy J, Engelhardt K, Cox K, Jacquet J, McDade A, Boyer M, Beale P, Stockler M, Loneragan R, Dennien B, et al: Long-term outcome of radiological-guided insertion of implanted central venous access port devices (CVAPD) for the delivery of chemotherapy in cancer patients: Institutional experience and review of the literature. Br J Cancer 91: 1045-1049, 2004.

10. Biffi R, de Braud F, Orsi F, Pozzi S, Mauri S, Goldhirsch A, Nolè $\mathrm{F}$ and Andreoni B: Totally implantable central venous access ports for long-term chemotherapy. A prospective study analyzing complications and costs of 333 devices with a minimum follow-up of 180 days. Ann Oncol 9: 767-773, 1998.

11. Fragou M, Gravvanis A, Dimitriou V, Papalois A, Kouraklis G, Karabinis A, Saranteas T, Poularas J, Papanikolaou J, Davlouros P, et al: Real-time ultrasound-guided subclavian vein cannulation versus the landmark method in critical care patients: A prospective randomized study. Crit Care Med 39: 1607-1612, 2011.

12. Mori Y, Nagayama S, Kawamura J, Hasegawa S, Tanaka E, Okabe H, Takeuchi M, Sonobe M, Matsumoto S, Kanai M, et al: A retrospective analysis on the utility and complications of upper arm ports in 433 cases at a single institute. Int J Clin Oncol 21: 474-482, 2016.

13. Shiono M, Takahashi S, Kakudo Y, Takahashi M, Shimodaira H, Kato S and Ishioka C: Upper arm central venous port implantation: A 6-Year single institutional retrospective analysis and pictorial essay of procedures for insertion. PLoS One 9: e91335, 2014.

14. Li Y, Cai Y, Gan X, Ye X, Ling J, Kang L, Ye J, Zhang X, Zhang J, Cai Y, et al: Application and comparison of different implanted ports in malignant tumor patients. World J Surg Oncol 14: 251, 2016.

15. Pikwer A, Åkeson J and Lindgren S: Complications associated with peripheral or central routes for central venous cannulation. Anaesthesia 67: 65-71, 2012.

16. Todd J: Peripherally inserted central catheters and their use in i.v. therapy. Br J Nurs 8: 140-2, 144, 146-8, 1999.

17. Ahn DH, Illum HB, Wang DH, Sharma A and Dowell JE: Upper extremity venous thrombosis in patients with cancer with peripherally inserted central venous catheters: A retrospective analysis of risk factors. J Oncol Pract 9: e8-e12, 2013.

18. Aw A, Carrier M, Koczerginski J, McDiarmid S and Tay J: Incidence and predictive factors of symptomatic thrombosis related to peripherally inserted central catheters in chemotherapy patients. Thromb Res 130: 323-326, 2012.

19. Kang MJ, Ryoo BY, Ryu MH, Koo DH, Chang HM, Lee JL, Kim TW and Kang YK: Venous thromboembolism (VTE) in patients with advanced gastric cancer: An Asian experience. Eur J Cancer 48: 492-500, 2012.

20. Heit JA, Silverstein MD, Mohr DN, Petterson TM, O'Fallon WM and Melton LJ III: Risk factors for deep vein thrombosis and pulmonary embolism: A population-based case-control study. Arch Intern Med 160: 809-815, 2000. 
21. Blom JW, Doggen CJ, Osanto S and Rosendaal FR: Malignancies, prothrombotic mutations, and the risk of venous thrombosis. JAMA 293: 715-722, 2005.

22. Liu Y, Gao Y, Wei L, Chen W, Ma X and Song L: Peripherally inserted central catheter thrombosis incidence and risk factors in cancer patients: A double-center prospective investigation. Ther Clin Risk Manag 11: 153-160, 2015.

23. Japanese Gastric Cancer Association: Japanese classification of gastric carcinoma: 3rd English edition. Gastric Cancer 14: 101-112, 2011.

24. Akahane A, Sone M, Ehara S, Kato K, Tanaka R and Nakasato T: Subclavian vein versus arm vein for totally implantable central venous port for patients with head and neck cancer: A retrospective comparative analysis. Cardiovasc Intervent Radiol 34 $1222-1229,2011$

25. Kawamura J, Nagayama S, Nomura A, Itami A, Okabe H, Sato S Watanabe $G$ and Sakai Y: Long-term outcomes of peripheral arm ports implanted in patients with colorectal cancer. Int J Clin Oncol 13: 349-354, 2008.

26. Lin WY, Lin CP, Hsu CH, Lee YH, Lin YT, Hsu MC and Shao YY: Right or left? Side selection for a totally implantable vascular access device: A randomised observational study. Br J Cancer 117: 932-937, 2017.

27. Loughran SC and Borzatta M: Peripherally inserted central catheters: A report of 2506 catheter days. JPEN J Parenter Enteral Nutr 19: 133-136, 1995.

28. Tran H, Arellano M, Chamsuddin A, Flowers C, Heffner LT, Langston A, Lechowicz MJ, Tindol A, Waller E, Winton EF and Khoury HJ: Deep venous thromboses in patients with hematological malignancies after peripherally inserted central venous catheters. Leuk Lymphoma 51: 1473-1477, 2010

29. Patel GS, Jain K, Kumar R, Strickland AH, Pellegrini L, Slavotinek J, Eaton M, McLeay W, Price T, Ly M, et al: Comparison of peripherally inserted central venous catheters (PICC) versus subcutaneously implanted port-chamber catheters by complication and cost for patients receiving chemotherapy for non-haematological malignancies. Support Care Cancer 22: 121-128, 2014

30. Chen IC, Hsu C, Chen YC, Chien SF, Kao HF, Chang SY, Hu FC and Yeh KH: Predictors of bloodstream infection associated with permanently implantable venous port in solid cancer patients. Ann Oncol 24: 463-468, 2013.

31. Ji L, Yang J, Miao J, Shao Q, Cao Y and Li H: Infections related to totally implantable venous-access ports: Long-term experience in one center. Cell Biochem Biophys 72: 235-240, 2015.

32. Wang TY, Lee KD, Chen PT, Chen MC, Chen YY, Huang CE, Kuan FC, Chen CC and Lu CH: Incidence and risk factors for central venous access port-related infection in Chinese cancer patients. J Formos Med Assoc 114: 1055-1060, 2015.

33. Kuderer NM, Ortel TL and Francis CW: Impact of venous thromboembolism and anticoagulation on cancer and cancer survival. J Clin Oncol 27: 4902-4911, 2009.

34. Zakai NA, Wright $\mathrm{J}$ and Cushman M: Risk factors for venous thrombosis in medical inpatients: Validation of a thrombosis risk score. J Thromb Haemost 2: 2156-2161, 2004.

35. Sallah S, Wan JY and Nguyen NP: Venous thrombosis in patients with solid tumors: Determination of frequency and characteristics. Thromb Haemost 87: 575-579, 2002.

36. Trousseau A: Plegmasia alba dolens. Lectures on clinical medicine, delivered at the Hotel-Dieu, Paris, Vol. 5. The New Sydenham Society, London, pp281-332, 1865.

37. Wolberg AS, Aleman MM, Leiderman K and Machlus KR: Procoagulant activity in hemostasis and thrombosis: Virchow's triad revisited. Anesth Analg 114: 275-285, 2012.
38. Wojtukiewicz MZ, Sierko E, Klement P and Rak J: The hemostatic system and angiogenesis in malignancy. Neoplasia 3: 371-384, 2001.

39. Larsen AC, Dabrowski T, Frøkjær JB, Fisker RV, Iyer VV, Møller BK, Kristensen SR and Thorlacius-Ussing O: Prevalence of venous thromboembolism at diagnosis of upper gastrointestinal cancer. Br J Surg 101: 246-253, 2014

40. Quinn DA, Thompson BT, Terrin ML, Thrall JH Athanasoulis CA, McKusick KA, Stein PD and Hales CA: A prospective investigation of pulmonary embolism in women and men. JAMA 268: 1689-1696, 1992

41. Cogo A, Bernardi E, Prandoni P, Girolami B, Noventa F, Simioni P and Girolami A: Acquired risk factors for deep-vein thrombosis in symptomatic outpatients. Arch Intern Med 154: 164-168, 1994.

42. Goldhaber SZ, Savage DD, Garrison RJ, Castelli WP, Kannel WB, McNamara PM, Gherardi G and Feinleib M: Risk factors for pulmonary embolism: The framingham study. Am J Med 74: 1023-1028, 1983

43. Goldhaber SZ, Grodstein F, Stampfer MJ, Manson JE, Colditz GA, Speizer FE, Willett WC and Hennekens CH: A prospective study of risk factors for pulmonary embolism in women. JAMA 277: 642-645, 1997.

44. Walker AJ, West J, Card TR, Crooks C, Kirwan CC and Grainge MJ: When are breast cancer patients at highest risk of venous thromboembolism? A cohort study using English health care data. Blood 127: 849-857, 2016.

45. Debourdeau P, Espié M, Chevret S, Gligorov J, Elias A, Dupré PF, Desseaux K, Kalidi I, Villiers S, Giachetti S, et al: Incidence, risk factors, and outcomes of central venous catheter-related thromboembolism in breast cancer patients: The CAVECCAS study. Cancer Med 6: 2732-2744, 2017.

46. Jones D, Wismayer K, Bozas G, Palmer J, Elliott M and Maraveyas A: The risk of venous thromboembolism associated with peripherally inserted central catheters in ambulant cancer patients. Thromb J 15: 25, 2017.

47. Larsen AC, Frøkjær JB, Fisker RV, Iyer V, Mortensen PB, Yilmaz MK, Møller B, Kristensen SR and Thorlacius-Ussing O: Treatment-related frequency of venous thrombosis in lower esophageal, gastro-esophageal and gastric cancer-a clinical prospective study of outcome and prognostic factors. Thromb Res 135: 802-808, 2015.

48. Haddad TC and Greeno EW: Chemotherapy-induced thrombosis. Thromb Res 118: 555-568, 2016.

49. Bertoglio S, Faccini B, Lalli L, Cafiero F and Bruzzi P: Peripherally inserted central catheters (PICCs) in cancer patients under chemotherapy: A prospective study on the incidence of complications and overall failures. J Surg Oncol 113: 708-714, 2016.

50. O'Brien J, Paquet F, Lindsay R and Valenti D: Insertion of PICCs with minimum number of lumens reduces complications and costs. J Am Coll Radiol 10: 864-868, 2013.

51. Sud R and Khorana AA: Cancer-associated thrombosis: Risk factors, candidate biomarkers and a risk model. Thromb Res 123 (Suppl 4): S18-S21, 2009.

52. Shivakumar SP, Anderson DR and Couban S: Catheter-associated thrombosis in patients with malignancy. J Clin Oncol 27: 4858-4864, 2009. International (CC BY-NC-ND 4.0) License. 